Brazilian Journal

of Chemical

Engineering

\title{
PRODUCTION OF FATTY ACID METHYL ESTERS FROM AN OLIVE OIL INDUSTRY WASTE
}

\author{
M. S. Alvarez Serafini ${ }^{1,2 *}$ and G. M. Tonetto ${ }^{1,2}$ \\ ${ }^{1}$ Universidad Nacional del Sur, Departamento de Ingeniería Química, Blanca, Argentina. \\ E-mail: malvarezserafini@plapiqui.edu.ar, ORCID: 0000-0001-7434-498X; gtonetto@plapiqui.edu.ar \\ ${ }^{2}$ Consejo Nacional de Investigaciones Científicas y Técnicas, Blanca, Argentina.
}

(Submitted: October 25, 2017 ; Revised: May 28, 2018 ; Accepted: June 10, 2018)

\begin{abstract}
This work studies the synthesis of fatty acid methyl esters (FAME) using crude olive pomace oil as raw material and zinc stearate as catalyst. Pomace oil is a non-edible by-product of olive oil production. The oil was characterized. In order to reduce the plant pigment content in the oil, the liquid was contacted with a modified clay. An experimental design was applied to determine the optimum operating conditions to achieve the minimum pigment concentration and the maximum amount of recovered oil. Response surface methodology was used to study the relationship between process variables and the selected response variables. A mixed-level factorial design was used, and the studied responses were triglyceride and free fatty acid (FFA) conversion and FAME yield at $30 \mathrm{~min}$ of reaction time. Under optimum conditions (temperature $(\mathrm{T}): 140^{\circ} \mathrm{C}$, catalyst loading (C): $3 \mathrm{wt} \%$, initial molar ratio of the reactants (MR): 30 ), $98 \%$ and $67 \%$ of triglyceride and FFA conversions were achieved, with $84 \%$ of FAME yield. This study shows that pomace oil can be used as a raw material for biodiesel production. At short reaction times and under moderate operating conditions, it was possible to convert triglycerides and fatty acids selectively toward FAME.

Keywords: Alperujo; Olive pomace oil; Transesterification; Esterification; Biodiesel.
\end{abstract}

\section{INTRODUCTION}

Biodiesel is a sustainable alternative to petrodiesel obtained from vegetable oils or animal fats. It emits significantly lower amounts of NOx than petroleumderived diesel, has better lubricating properties, is biodegradable and less toxic. Since 2014, diesel fuel sold in Argentina must contain a minimum of $10 \%$ biodiesel component (Vicente et al., 2004).

Biodiesel consists of a mixture of mono-alkyl esters obtained from the transesterification of triglycerides or the esterification of free fatty acids with short chain alcohols. Argentina is currently one of the leading producers of biodiesel worldwide, using soybean oil as feedstock.

Biofuels obtained from human food products are called first generation fuels. This type of biodiesel accounts for more than $95 \%$ of the world total production (Hajjari et al., 2017). In addition to technical aspects, environmental and economic feasibility are also of great importance to access process viability. The use of vegetable oils suitable for consumption as raw material for biodiesel production has social and economic implications. These include the high costs of high-quality raw materials, the competition between crops for food and for fuel, with the resulting increase in food prices, and the impact on the use of the land (Kumar et al., 2017; Tomei and Uphamb, 2009). A cost analysis of biodiesel production using conventional alkali-catalyzed transesterification was carried out by Apostolakou et al. (2009). They determined that for small plants, the feedstock cost accounts for $75 \%$ of the total production costs, but it can increase to $90 \%$ for large plants. This is in agreement with the results obtained by Haas et al. (2010), who concluded that the $88 \%$ of the production cost can be attributed to the raw material. Marchetti et al. (2008) studied the biodiesel production from waste oil with $5 \%$ free fatty acids, and

\footnotetext{
* Corresponding authors: M. S. Alvarez Serafini - E-mail: malvarezserafini@plapiqui.edu.ar
} 
they found that between 76 and $80 \%$ of the operating cost was associated with the cost of the raw material.

For these reasons, studies are focusing on developing second-generation biodiesel with alternative technologies capable of using low-cost raw materials, as well as non-edible oils and waste from the food industry, such as animal fats and lowquality vegetable oils, or used frying oils (Jefferson, 2006; McKendry, 2002). The production of biodiesel from biomass waste reduces the contribution of fuel production to food prices and helps to improve the economic viability of biodiesel (Abu-Jrai, 2017; Vicente et al., 2009).

Olive pomace, also called "alperujo", is a by-product of olive oil extraction by the two-phase decanter process. It consists of water, lignin, hemicellulose and cellulose, carbohydrates, fats and polyphenols (Hernández et al., 2014; Barbaro et al. 2014). Disposal of alperujo into the soil can cause serious environmental problems because it has phytotoxic activity that does not allow plants to germinate. Olive plantations in Argentina are expanding rapidly (Rousseaux et al., 2008), and consequently alperujo is an environmental waste that should be valorized. This waste is a good source of bioenergy due to its large calorific value. It could be used to obtain thermal or electric energy through combustion (Roig et al., 2006) or gasification (Jurado et al., 2003).

The environmental impact of biodiesel production from olive pomace oil (B20 and B100) and petroleum diesel were compared through life-cycle assessment (Rajaeifar et al., 2016). In addition, energy and economic analyses of biodiesel production from pomace oil were also carried out. They concluded that, among the studied categories, the biodiesel obtained from pomace oil was much better than conventional fuel for the categories climate change and resource damage. The economic analysis showed the economic viability of biodiesel production from pomace oil.

Homogeneous alkaline catalysts, such as sodium and potassium hydroxides and methoxides are used in the industry for the production of biodiesel. The main drawbacks are the difficulty in using low-cost raw materials due to the presence of free fatty acids (FFA) and water, and the complexity in the separation and purification stages. Further studies are needed on alternative technologies that may be used with acidic raw materials. Zhang et al. (2003a; 2003b) performed an economic assessment of biodiesel production plants using waste vegetable oil as feedstock, and they concluded that acid-catalyzed processes are technically feasible, less complex and an economical alternative to alkali processes. On the other hand, West et al. (2008) compared different catalysts for producing biodiesel, and they observed that the heterogeneous catalytic process using $\mathrm{SnO}$ was the least complex and the most economically attractive option. Homogeneously catalyzed processes require downstream equipment to neutralize the catalyst and also to purify and wash the biodiesel as well as the by-product (glycerol). Heterogeneous catalysts, such as solid acid or base, or immobilized lipases, offer a more environmentally friendly process due to the lack of those stages, and also allow operating with lower investment costs.

In the biodiesel production process, a catalyst that is active in both the transesterification and esterification reactions and that can be easily separated from the reaction media can simplify the subsequent purification step. In previous works (Reinoso et al., 2012, Reinoso et al., 2013), several zinc carboxylates were presented as active catalyst alternatives for biodiesel production under mild conditions. Zinc stearate is a solid at room temperature that is solubilized in the reaction medium at $100{ }^{\circ} \mathrm{C}$ and re-crystallizes at the end of the reaction. It is active in the presence of fatty acids and water, and it is non-toxic.

Although previous studies have been performed on the transesterification of alperujo oil, most of this research is based on the use of lipases and conventional acid and base homogenous catalysts (Yüsel, 201; Bonet-Ragel et al., 2015; Hernández et al., 2014; Lama-Muñoz et al., 2014).

One of the current challenges in the secondgeneration biofuel synthesis is the use of environmentally friendly catalysts that can conserve their activity (Hill et al., 2006; Chhetri et al., 2008; Demirbas, 2007; Nunes et al., 2009; Naik et al., 2010). The novelty of the present manuscript is that it shows the viability of using a very interesting catalyst in the production of biodiesel using biomass waste as feedstock.

This work presents the characterization of pomace oil and evaluates its potential to be used as raw material for the production of methyl esters of fatty acids (FAME) using zinc stearate as an ecofriendly catalyst under moderate reaction conditions. Response Surface Methodology was used to study the relationship between process variables (temperature, catalyst concentration and initial reactant ratio) and triglyceride and free fatty acid conversion and FAME yield.

\section{EXPERIMENTAL}

\section{Pomace oil characterization}

The acid value of pomace oil was determined according to the method described in AOCS Cd 3d-63, by titration using an ethanolic solution of potassium hydroxide and phenolphthalein as an indicator.

The determination of water in the oil was performed by Karl Fischer titration following the ASTM D6304 method, using the reaction of iodine with water. 
The peroxide value was determined according to the Official Method AOCS Cd 8-53, by titration of the liberated iodine with sodium thiosulphate solution. The result was expressed in terms of milliequivalents of active oxygen per $\mathrm{kg}$.

The fatty acid composition of pomace oil was obtained by gas chromatography (AGILENT 4890D) using a FID detector, according to the AOCS Ce 1c-89 standard. The Iodine Value of the oil was calculated from the fatty acid profile according to AOCS Cd 1c85.

The content of chlorophyll pigments in pomace oil was determined following the AOCS Official Method Cc 13i-96, measuring the absorbance at $670 \mathrm{~nm}$, and expressing it as $\mathrm{mg}$ of pheophytin a in $1 \mathrm{~kg}$ of oil.

In order to know the concentration of phosphorus in the pomace oil, the acid-soluble ashes were obtained according to the AOCS Official Method Ca 12-55, from a sample of oil and zinc oxide, dissolving the soluble ashes with hot dilute hydrochloric acid and filtering. The determination of the total phosphorus content was done by inductively coupled plasma (ICP) spectrometry of the resulting solution.

The oil was analyzed by diffuse reflectance infrared Fourier transform spectroscopy (DRIFTS, Nicolet 6700 FT-IR spectrometer), in the $4000-400 \mathrm{~cm}^{-1}$ region. The spectra were recorded with a $4 \mathrm{~cm}^{-1}$ resolution and 64 scans.

\section{Pretreatment of the crude pomace oil}

The pomace oil was purified using a modified clay (Tonsil Supreme 167, donated by Refil S.A) to remove the plant pigments (chlorophyll). A $3.2^{2} \mathrm{mix}$ level factorial design, with one central point and a total of 13 experiments, was applied in this study. The variables and their levels were: clay content $(3,5$ and $7 \%$ ), process temperature $\left(70,80,90{ }^{\circ} \mathrm{C}\right)$ and contact time $(15,30,45 \mathrm{~min})$. The studied responses were: chlorophyll pigment concentration (mg pheophytin/kg oil) and recovered oil (\%). The separation of the pomace oil from the clay was performed by centrifugation.

The experimental factorial design and the statistical analysis were performed using the STATGRAPHICS Centurion version XV.2 software. The factors and levels used and the obtained experimental responses are presented in Table 2 . The order of the experiments was fully randomized to protect against the effects of lurking variables.

\section{Catalytic tests}

The zinc stearate catalyst was obtained from the metathesis reaction in alcoholic solution (Barman and Vasudevan, 2006). The sodium stearate salt was prepared first. The obtained precipitate was dissolved in water, and a stoichiometric amount of $\mathrm{ZnCl}_{2}$ was added. The resulting precipitate was stirred for $1 \mathrm{~h}$, then filtered, washed and dried at $50{ }^{\circ} \mathrm{C}$ for $24 \mathrm{~h}$. The catalyst structure (synthesized and recovered after reaction) was validated by X-ray diffraction (Philips $\mathrm{PW} 1710$, using $\mathrm{Cu} \mathrm{K} \alpha$ radiation scan in the $2 \theta$ range of 2-60 $)$ and by diffuse-reflectance infrared Fourier transform spectroscopy (DRIFTS, Nicolet 6700 FT-IR spectrometer).

Crude alperujo oil was used as feedstock (harvest 2015, donated by Olivsan, Argentina) and methanol grade HPLC (Aberkon). The reactions were carried out in a $600 \mathrm{ml}$ Parr batch reactor. The stirring rate was set at $500 \mathrm{rpm}$ to ensure the absence of external mass transfer resistance (Reinoso et al., 2012).

In order to evaluate the effects of the selected variables on the response variables, a $3.2^{2}$ mix factorial design was developed with 2 center point replicates, with a total of 14 experiments, as shown in Table 3. The order of the experiments was fully randomized to provide protection against the effects of lurking variables. The variables were methanol/oil molar ratio, temperature and catalyst loading. The initial molar ratio was 10,20 and 30 , the reaction temperature was 100,120 and $140^{\circ} \mathrm{C}$, and the catalyst loading was 1,2 and $3 \%$ (with respect to oil). At temperatures higher than $140{ }^{\circ} \mathrm{C}$, the catalyst can be transformed into $\mathrm{Zn}$ glycerolate (Reinoso et al., 2014; Reinoso et al., 2015).

Catalytic tests were performed for 30 min reaction time for the experimental design, and for $360 \mathrm{~min}$ in order to determine equilibrium concentration.

The studied responses were triglyceride conversion $\left(\mathrm{X}_{\mathrm{TG}}\right)$, FFA conversion $\left(\mathrm{X}_{\mathrm{FFA}}\right)$ and FAME yield $\left(\mathrm{Y}_{\mathrm{FAME}}\right)$ evaluated at $30 \mathrm{~min}$ of reaction time. The responses were calculated as follows:

$$
\begin{aligned}
& \mathrm{X}_{\mathrm{FFA}}=\frac{\mathrm{FFA}_{0}-\mathrm{FFA}_{\mathrm{f}}}{\mathrm{FFA}_{0}} \\
& \mathrm{X}_{\mathrm{TG}}=\frac{\mathrm{TG}_{0}-\mathrm{TG}_{\mathrm{f}}}{\mathrm{TG}_{0}} \\
& \mathrm{Y}_{\mathrm{FAME}}=\frac{\mathrm{FFA} / 3}{\mathrm{TGE}_{0}}
\end{aligned}
$$

where $\mathrm{TG}_{\mathrm{i}}$ and $\mathrm{FFA}_{\mathrm{i}}$ correspond to the concentration of triglycerides and free fatty acids, respectively, and the subscripts " $\mathrm{i}$ " are 0 for the initial and $\mathrm{f}$ for the final time. $\mathrm{TGE}_{0}$ represents the initial equivalent triglycerides moles:

$$
\mathrm{TGE}_{0}=\mathrm{TG}_{0}+\mathrm{FFA}_{0} / 3
$$

The software STATGRAPHICS Centurion version XV.2 was used for both the experimental design and the statistical analysis. The responses were adjusted 
by multiple regression, and the generated models were used to evaluate the effect of the selected experimental factors. The goodness of the fit was assessed using the coefficient of determination $\left(\mathrm{R}^{2}\right)$. The statistically significant effect of the variables was tested using the ANOVA statistical test. Non-significant coefficients were eliminated ( $p$-value $>0.05$ ) and the models were refined in order to consider only the statistically significant effects.

The quantification of the products and reactants was performed by gas chromatography according to the UNE-EN norm 14105, using a Perkin Elmer AutoSystem XL chromatograph equipped with a capillary column (ZB-5HT Zebron) and a FID detector. The FFA content was determined by acid-base titration (UNE-EN norm 14104).

\section{Kinetic model}

The overall transesterification reaction can be presented by the following equation:

$\mathrm{TG}+3 \mathrm{MOH} \leftrightarrow 3 \mathrm{FAME}+$ Gly

where $\mathrm{MOH}$ is methanol and Gly is glycerol.

On the other hand, the esterification reaction can be expressed as follows:

$$
\mathrm{FFA}+\mathrm{MOH} \leftrightarrow \mathrm{FAME}+\mathrm{H}_{2} \mathrm{O}
$$

A simple kinetic model was utilized in order to model the process. The reaction mixture was assumed to be pseudo-homogeneous, perfectly mixed with no mass transfer limitation (Reinoso et al., 2012) and the reaction irreversible second-order in the early period (Marjanivic et al., 2010; Zubir and Chin, 2010). According to the assumptions, the reaction rate for the transesterification reaction is:

$$
-r_{\mathrm{A}}=-\frac{\mathrm{dC}_{\mathrm{TG}}}{\mathrm{dt}}=\mathrm{kC}_{\mathrm{TG}}^{2}
$$

where $\mathrm{C}_{\mathrm{TG}}$ is the triglyceride concentration, and can be expressed in terms of conversion as:

$$
\mathrm{C}_{\mathrm{TG}}=\mathrm{C}_{\mathrm{TG} 0}\left(1-\mathrm{X}_{\mathrm{TG}}\right)
$$

where $\mathrm{C}_{\mathrm{TG} 0}$ is the initial TG concentration. From the combinations of Eq. 7 and 8 one obtains:

$$
-\frac{\mathrm{dx}_{\mathrm{TG}}}{\mathrm{dt}}=\mathrm{kC}_{\mathrm{TG} 0}\left(1-\mathrm{X}_{\mathrm{TG}}\right)^{2}
$$

And after integration:

$$
\frac{\mathrm{x}_{\mathrm{TG}}}{1-\mathrm{x}_{\mathrm{TG}}}=\mathrm{kC}_{\mathrm{TG} 0} \mathrm{t}
$$

The reaction rate constant $\mathrm{k}$ can be obtained from the slope of Eq. 10.

Making the same combinations, the equation for the esterification reaction becomes (Eq. 11):

$$
\frac{\mathrm{X}_{\mathrm{FFA}}}{1-\mathrm{X}_{\mathrm{FFA}}}=\mathrm{kC}_{\mathrm{FFA} 0} \mathrm{t}
$$

\section{RESULTS}

\section{Catalyst characterization}

The catalyst was characterized in order to corroborate the correct synthesis. Figure 1 shows the infrared spectrum (a) and the XRD pattern (b) obtained from the catalyst sample.

In Figure 1(a), the strong absorption bands located between 2800 and $3000 \mathrm{~cm}^{-1}$ correspond to the vibrations of symmetric and antisymmetric deformation of the C-H bond. Additionally, the weak signals between 750 and $1350 \mathrm{~cm}^{-1}$ are characteristics of the coupling of the scissoring, rocking and stretching vibrations of the groups $\mathrm{CH}_{2}$ and $\mathrm{CH}_{3}$, while the signals at 721 and $1460 \mathrm{~cm}^{-1}$ correspond to the rocking and scissoring vibrations of the $\mathrm{CH}_{2}$ group, respectively.

The three intense bands located at 1390, 1460 and $1540 \mathrm{~cm}^{-1}$ are attributed to the coupling of the vibrational modes of symmetric and antisymmetric deformations of the COO- bond of the carboxylic group. The absorption band located in the region of $430-470 \mathrm{~cm}^{-1}$ corresponds to the vibration of the O-Zn bond.

The diffractogram in Figure 1.b indicates that zinc stearate is a solid material with crystalline regions and also has a weakly crystallin region formed during the precipitation process. The three peaks of maximum
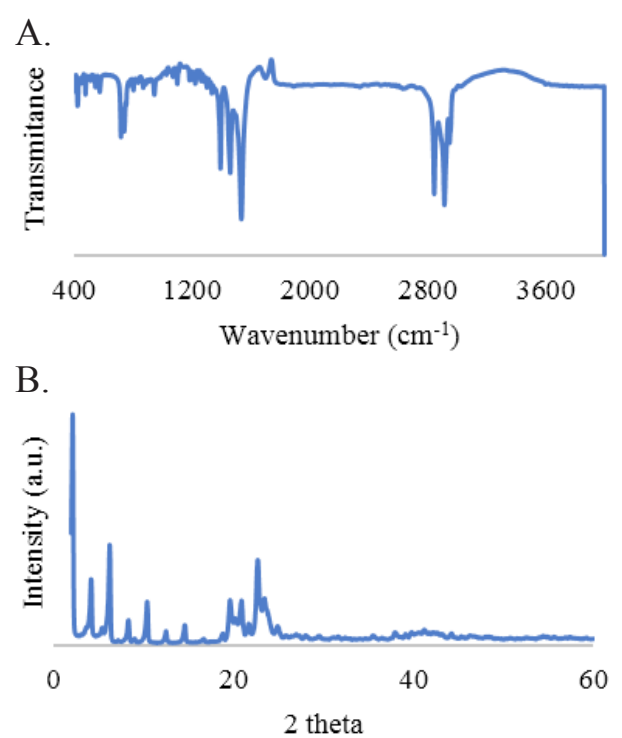

Figure 1. Infrared spectra (a) and XRD pattern (b) of zinc stearate. 
intensities that can be used to identify zinc stearate are those corresponding to $2 \Theta=2.21,4.25$ and 6.33 .

\section{Characterization of raw pomace oil}

The crude alperujo oil has a dark green color and a strong characteristic odor. Figure 2 shows the IR spectrum of the pomace oil and the one corresponding to extra virgin olive oil (presented as a reference). The main IR peaks present between 3100 and $2800 \mathrm{~cm}^{-1}$ are due to asymmetrical and symmetrical C-H stretching, and those at 1450 and $1380 \mathrm{~cm}^{-1}$ correspond to bending vibrations of $\mathrm{C}-\mathrm{H}$ (Roman and Che Man, 2010; Lerma-Garcia et al., 2010). The peak at $1743 \mathrm{~cm}^{-1}$ is assigned to the ester carbonyl group, and the signals at 1228 and $1160 \mathrm{~cm}^{-1}$ correspond to C-O stretching. The peaks at 1120 and $1090 \mathrm{~cm}^{-1}$ are assigned to stretching vibrations of the $\mathrm{C}-\mathrm{O}$ ester group. The signal at 3010 $\mathrm{cm}^{-1}$ corresponds to cis double-bond stretching, while the peak at $950 \mathrm{~cm}^{-1}$ is assigned to trans olefins. No differences were observed between the spectra obtained for the pomace oil and the extra virgin olive oil, except for the signal attributed to trans olefins. This latter is a consequence of the extraction process of each oil.

The chemical composition of the pomace oil, in term of fatty acid composition, is shown in Table 1. The oleic acid is the predominant fatty acid, followed by palmitic acid. The iodine value of the sample was $75 \mathrm{~g} \mathrm{I} / 100 \mathrm{~g}$ oil and agrees with the value presented in CODEX STAN 33-1981 norm for olive and pomace oils.

It is well known that the vegetable oils used as a raw material for biodiesel production should be almost free of water and FFA since the presence of both of them has negative effects on the transesterification reaction (Komers et al., 2001). The measured water content in the crude alperujo oil was $0.07 \%$ and its acid value was $2.3 \mathrm{mg} \mathrm{KOH} / \mathrm{g}$ oil (1.16\% oleic acid).
Table 1. Fatty acid distribution in pomace oil.

\begin{tabular}{ccc}
\hline \multicolumn{1}{c}{ Fatty acid } & Content (wt\%) \\
\hline Palmitic acid & C16:0 & 20.5 \\
Palmitoleic & C16:1c & 2.0 \\
Stearic acid & C18:0 & 4.6 \\
Oleic & C18:1t & 3.6 \\
Oleic acid & C18:1c & 55.4 \\
Linoleic acid & C18:2cc & 13.8 \\
\hline
\end{tabular}

Both values are higher than those recommended by Ma et al. (1998), who concluded that the water content of the oil should be less than $0.06 \mathrm{wt} \%$ and $0.5 \mathrm{wt} \%$ for FFA content to be used in the reaction catalyzed by a homogeneous alkali catalyst.

The calculated peroxide value was $8.7 \mathrm{meq} / \mathrm{kg}$ oil. Since it was less than $10 \mathrm{meq} / \mathrm{kg}$ oil, there was no evidence of initial rancidity in the unsaturated oil.

Untreated crude alperujo oil has poor oxidation stability due to the presence of the high chlorophyll content. This can be improved by pre-treating the oil. The concentration of chlorophyll pigments was $77 \mathrm{mg}$ pheophytin $/ \mathrm{kg}$ oil. The value determined for a commercial extra virgin olive oil was $9 \mathrm{mg}$ pheophytin/ $\mathrm{kg}$ oil, and close to zero for soybean oil.

The phosphorus content in the oil was $0.66 \mathrm{mg} / \mathrm{kg}$. Since it is a crude oil, this value corresponds to organic and inorganic phosphorus.

\section{Pretreatment of the crude alperujo oil}

In order to reduce the plant pigment content in the pomace oil, and produce biodiesel with improved oxidation stability, the crude oil was contacted with a modified clay (Tonsil Supreme) as shown in Table 2.

The quadratic model obtained from the experimental data for the chlorophyll content is presented in Eq. 12. This model was adjusted by stepwise selection (Fisher's test). Since the P-value for the temperature variable in ANOVA was greater than 0.05 , there was

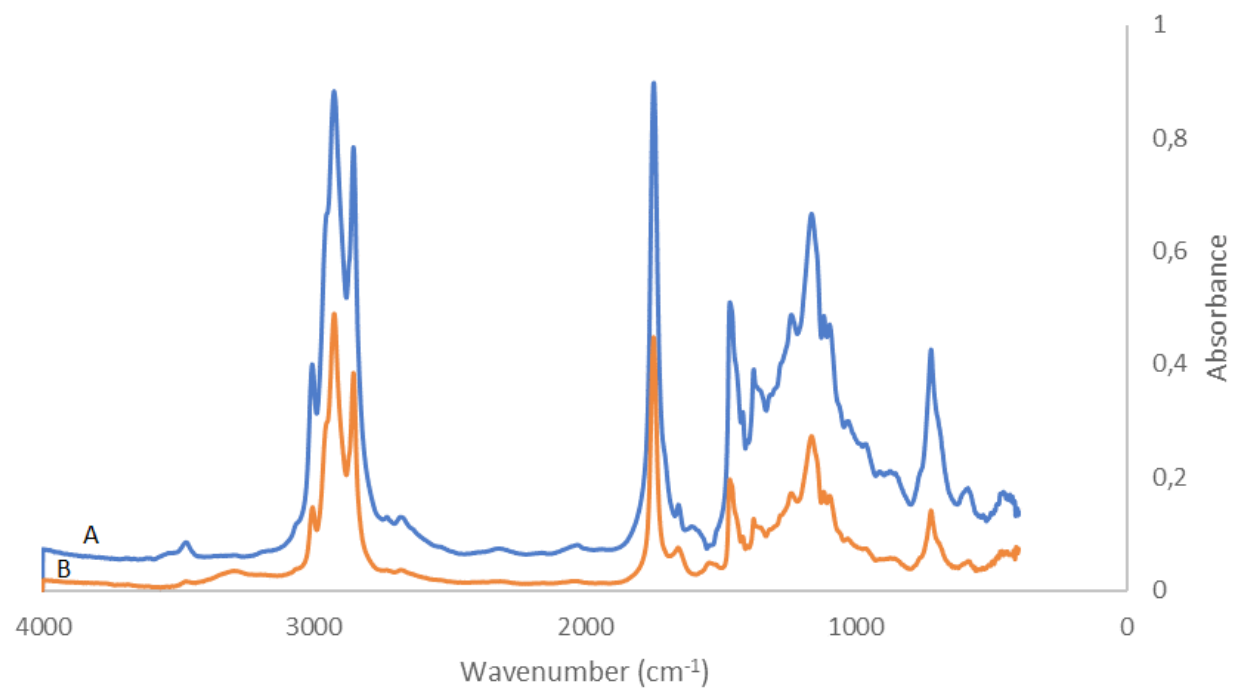

Figure 2. Infrared spectra of raw pomace oil (A) and extra-virgin olive oil (B). 
Table 2. $3.2^{2}$ experimental design carried out for the pretreatment of the pomace oil.

\begin{tabular}{ccccc}
\hline $\begin{array}{c}\text { Temperature } \\
\left(\mathbf{O}^{\mathbf{C}} \mathbf{C}\right)\end{array}$ & $\begin{array}{c}\text { Clay } \\
(\mathbf{w t} \%)\end{array}$ & $\begin{array}{c}\text { Time } \\
(\mathbf{m i n})\end{array}$ & $\begin{array}{c}\text { Chlorophyll } \\
\text { pigments } \\
\text { (mg pheophytin } \\
\text { /kg oil) }\end{array}$ & $\begin{array}{c}\text { Recovered } \\
\text { oil } \\
\mathbf{( \% )}\end{array}$ \\
\hline 90 & 3 & 15 & 52.8 & 93 \\
70 & 7 & 15 & 4.9 & 83 \\
80 & 3 & 15 & 37.4 & 93 \\
80 & 7 & 45 & 0.8 & 86 \\
90 & 7 & 45 & 0.4 & 90 \\
70 & 7 & 45 & 1.6 & 90 \\
80 & 7 & 15 & 2.0 & 86 \\
90 & 7 & 15 & 0.5 & 90 \\
80 & 3 & 45 & 19.2 & 96 \\
80 & 5 & 30 & 1.1 & 93 \\
90 & 3 & 45 & 18.3 & 96 \\
70 & 3 & 15 & 65.3 & 96 \\
70 & 3 & 45 & 26.4 & 93 \\
\hline
\end{tabular}

not a statistically significant effect of this variable on the process in the selected range of work (at the $95.0 \%$ confidence level).

Chlorophyll content $=\left\{\begin{array}{c}\mathrm{f}=209,739-61,0769 \mathrm{X}-1,74127 \mathrm{Y}+0,24125 \mathrm{XY}+4,51148 \mathrm{X}^{2} \text { if } \mathrm{f}>0 \\ \mathrm{f}=0 \quad \text { otherwise }\end{array}\right.$

where $\mathrm{X}$ is the clay content $(\%)$ and $\mathrm{Y}$ is the contact time $(\mathrm{min})$, for temperature $=80^{\circ} \mathrm{C}$.

Since negative values of chlorophyll concentration have no physical meaning, the equation was modified as shown in Equation 13, and the resulting surface response graph is shown in Figure 3, which shows the effect of the contact time and the clay content on the chlorophyll pigment concentration.

The model and the plot shown in Fig. 3 were obtained using the STATGRAPHICS Centurion software, and they explain $94.5 \%$ of the variability in the studied variable. Figure 3 shows that the highest

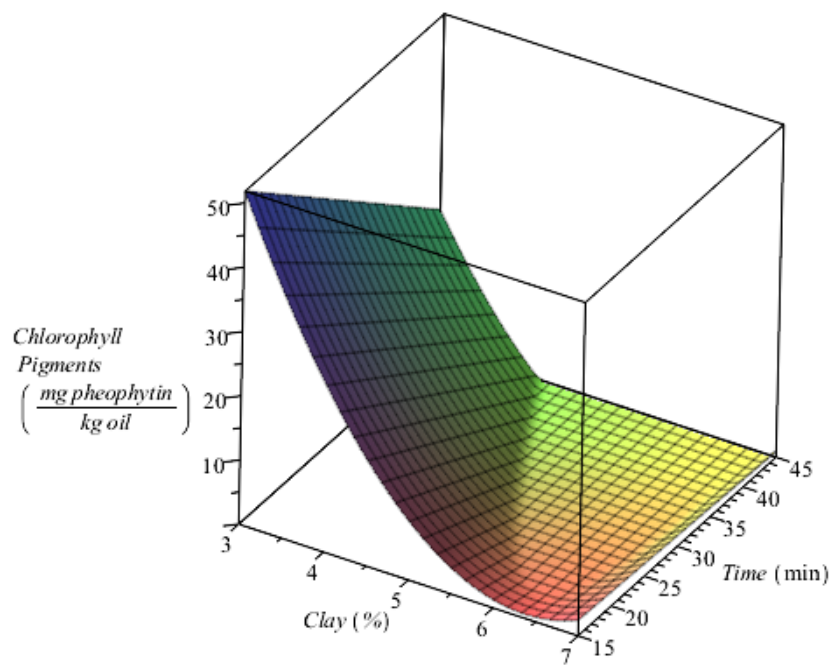

Figure 3. Removal of chlorophyll pigment: effect of the clay content and the contact time (Temperature: $\left.70^{\circ} \mathrm{C}\right)$. values of time and clay content generated the best results for chlorophyll removal.

Regarding the recovered oil, it can be seen in Table 2 that the main variable affecting these studied responses is the clay content (the only studied variable with a p-value lower than 0.05 in ANOVA). When the latter increases, the recovered oil decreases.

As a result of this experimental study, the following conditions were selected for the purification process: time: $35 \mathrm{~min}$, temperature: $70^{\circ} \mathrm{C}$, clay: $5 \mathrm{wt} \%$.

It was possible to remove the chlorophyll content to levels not detected by the method used (AOCS Cc 13i-96 Method).

In Figure 4, the pomace oil is shown before and after the extraction of the pigments. In the bottom of the container the clay deposited after being centrifuged can be observed.

The phosphorus content after the pretreatment was less than $0.11 \mathrm{mg} / \mathrm{kg}$. According to the norm EN14107, the phosphorus content for biodiesel must be less than $10 \mathrm{mg} / \mathrm{kg}$.

In the oil industry, color is one of the most important quality criteria for the commercial value of this oil. The refinement of a crude edible oil includes four steps: degumming, neutralization, bleaching and deodorization. The bleaching step is carried out using an acid activated clay and this process produces large amounts of solid waste. The cost of the bleaching earth is important to the process and, in addition, its elimination causes environmental pollution and is a source of bad odors and fire hazards. There are many studies researching how to minimize the risk of pollution and add value to these wastes. Foletto et al. (2002) recycled an acid-activated clay previously used in the soybean oil industry through an extraction process using organic solvents to remove residual oil, followed by reactivation by thermal treatment. The regenerated clay samples showed a similar efficacy in the decolorization of soybean oil than when using a commercial virgin clay. Also, the effectiveness

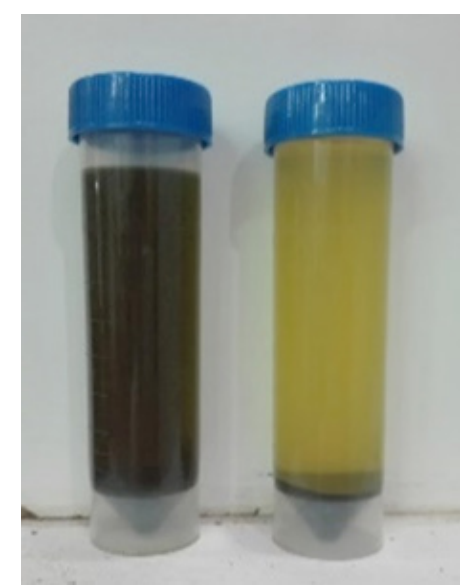

Figure 4. Raw pomace oil before (left) and after (right) treatment with a modified clay. 
of a thermal process followed by activation with hydrochloric acid for a spent decolorizing earth (Boukerroui and Ouali, 2000) was reported. Alhamed and Al-Zahrani (1999) studied a recovery process of depleted earth oil by solvent extraction followed by the reactivation by acid treatment and they concluded that the suggested process is economically viable.

Efforts have been made to extract the residual oil using different solvents (methanol, ethanol, petroleum ether and hexane) and use it as raw material in the transesterification reaction. Lim et al. (2009) studied the synthesis of biodiesel from the oils recovered from the clay generated in the refineries. They obtained 98.6\% of FAME using $\mathrm{CaO}$ as a catalyst. Huang and Chang (2010) obtained $85 \%$ of FAME in the transesterification reaction of the oil recovered from the residual clay using $\mathrm{NaOH}$ as a catalyst. In addition, they worked on an economic analysis that showed that the cost of producing biodiesel under these conditions was lower than that obtained from refined vegetable oils or waste cooking oils.

\section{Catalytic tests: experimental design}

Table 3 presents the experimental results for the reaction between pomace oil and methanol catalyzed by $\mathrm{Zn}$ stearate for $30 \mathrm{~min}$ reaction time, following the experimental design presented above. Table 4 shows the values of the initial concentration for all runs of Table 3.

Table 5 lists all the equations obtained after multiple regression using the Statgraphics Centurion XV.2 software, the description of the responses, the

Table 3. $3.2^{2}$ Experimental design for the reaction between pomace oil and methanol (reaction time: 30 $\min$ ).

\begin{tabular}{cccccc}
\hline $\begin{array}{c}\text { Temperature } \\
\left({ }^{\circ} \mathbf{C}\right)\end{array}$ & $\begin{array}{c}\text { Catalyst } \\
\text { loading } \\
(\mathbf{w t} \%)\end{array}$ & $\begin{array}{c}\text { Molar } \\
\text { ratio } \\
(\mathbf{m o l} / \mathbf{m o l})\end{array}$ & $\begin{array}{c}\text { TG } \\
\text { conversion } \\
(\%)\end{array}$ & $\begin{array}{c}\text { FAME } \\
\text { yield } \\
(\%)\end{array}$ & $\begin{array}{c}\text { FFA } \\
\text { conversion } \\
(\%)\end{array}$ \\
\hline 100 & 1 & 10 & 20.6 & 8.3 & 33.3 \\
140 & 3 & 30 & 98.1 & 84.1 & 67.3 \\
140 & 1 & 30 & 90.5 & 64.4 & 60.6 \\
120 & 2 & 20 & 67.6 & 33.8 & 57.7 \\
120 & 3 & 10 & 62.6 & 32.3 & 58.2 \\
120 & 1 & 30 & 56.7 & 26.5 & 49.2 \\
120 & 3 & 30 & 79.9 & 46.8 & 61.8 \\
100 & 3 & 10 & 29.2 & 11.6 & 24.4 \\
140 & 3 & 10 & 80.2 & 53.7 & 61.8 \\
120 & 2 & 20 & 70.0 & 36.2 & 57.6 \\
120 & 1 & 10 & 43.5 & 19.4 & 41.8 \\
100 & 3 & 30 & 33.8 & 13.0 & 54.6 \\
100 & 1 & 30 & 16.3 & 6.5 & 31.2 \\
140 & 1 & 10 & 72.9 & 43.9 & 53.2 \\
\hline
\end{tabular}

Table 4. Values of initial concentration of FFA and TG.

\begin{tabular}{ccc}
\hline $\begin{array}{c}\text { Molar ratio } \\
\text { (mol:mol) }\end{array}$ & $\begin{array}{c}\mathbf{C}_{\text {TG,0 }} \\
(\mathbf{m o l} / \mathbf{L})\end{array}$ & $\begin{array}{c}\mathbf{C}_{\text {FFA, }} \\
(\mathbf{m o l} / \mathbf{L})\end{array}$ \\
\hline 10 & 0.74 & 0.0364 \\
20 & 0.57 & 0.0354 \\
30 & 0.46 & 0.0348 \\
\hline
\end{tabular}

equation numbers, the percentages of variation of the parameters explained using $\mathrm{R}^{2}$, the $\mathrm{p}$-values, and the F-values. Second-order models allowed a good adjustment of the experimental data. They were refined by applying the F-test, also called the Fisher-Snedecor test (Besset, 2001).

\section{FFA esterification}

The conversion of FFA presented values between 24 and $67 \%$ under the studied conditions (Table 3 ).

According to the ANOVA test result, temperature $(\mathrm{p}$-value $=0.0023)$ and the catalyst loading $(\mathrm{p}$-value $=$ 0.0496 ) were the most important parameters affecting the FFA conversion. Under the selected operating conditions, methanol:oil molar ratio did not affect significantly the esterification reaction.

Equation 14 accounted for $85.92 \%$ of the changes observed in the conversion of FFA. The surface response graph presented in Figure 5 shows the effect of the variables on the consumption of fatty acids, for an initial molar ratio of 20 . It can be seen that the highest conversion was obtained with the greatest values of temperature and catalyst loading.

\section{Triglyceride transesterification}

The conversion of TG presented values between 16 and $98 \%$ under the studied conditions. According

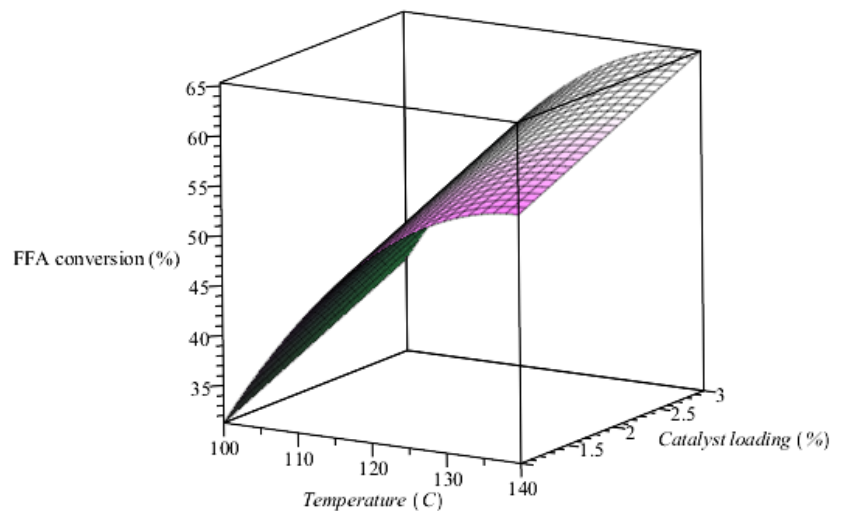

Figure 5. Esterification of FFA in pomace oil: efect of the temperature and catalyst loading (molar ratio of methanol:oil $=20: 1)$.

Table 5. Results of the data fitting with STATGRAPHICS Centurion software of the studied responses. Reference: A: temperature, B: catalyst loading, C: molar ratio.

\begin{tabular}{ccccc}
\hline Response & Equation & $\mathbf{R}^{\mathbf{2}} \mathbf{( \% )}$ & p-value & F-value \\
\hline $\mathrm{X}_{\mathrm{FFA}}$ & $-248.356+4.27094 \mathrm{~A}+0.23012 \mathrm{C} \mathrm{B}-0.01521 \mathrm{~A}^{2}(14)$ & 85.92 & 0.0001 & 20.34 \\
$\mathrm{X}_{\mathrm{TG}}$ & $-425.271+6.44094 \mathrm{~A}+0.28918 \mathrm{~B} \mathrm{C}-0,02054 \mathrm{~A}^{2}(15)$ & 95.12 & 0.0000 & 64.93 \\
Y $_{\mathrm{FAME}}$ & $-56.0349+0.00539 \mathrm{~A}^{2}+0.28730 \mathrm{C} \mathrm{B} \quad(16)$ & 93.18 & 0.0000 & 75.09 \\
\hline
\end{tabular}


to the ANOVA test, all the studied variables affected $\mathrm{X}_{\mathrm{TG}}$ (p-values lower than 0.05). Figure 5 shows surface plots for the response obtained from Equation 15 , which correlates $X_{\mathrm{TG}}$ with the evaluated factors with a $\mathrm{R}^{2}=95.1 \%$. The increase in catalyst loading and methanol:oil ratio favored the conversion of triglycerides (Fig. 6.a). In the same way, the increase in temperature positively affected this response (Fig. $6 . b)$.

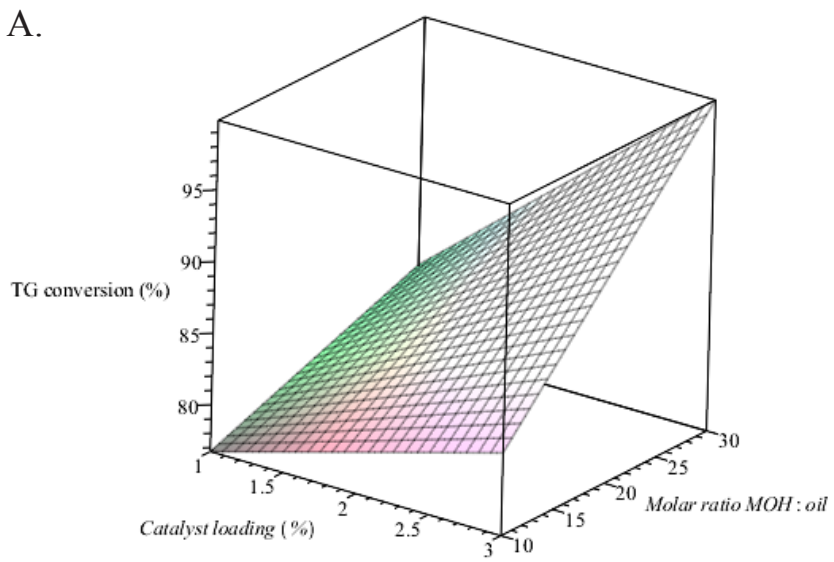

B.

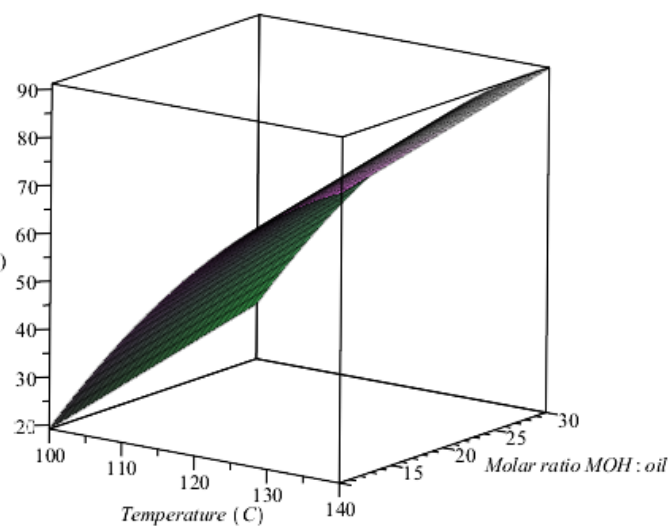

Figure 6. Triglyceride conversion in the tranesterification of pomace oil. Variables: (a) catalyst loading and initial molar ration $\mathrm{MOH}$ :oil (at $140{ }^{\circ} \mathrm{C}$ ), (b) temperature and initial molar ration $\mathrm{MOH}$ :oil (catalyst loading: $2 \%$ ).

\section{Fame yield}

Fame yield is the consequence of the simultaneous TG transesterification and FFA esterification. This parameter showed values between 6.5 and $84 \%$ after 30 min reaction time, under the studied conditions.

The relationship between FAME yield and the studied factors is given by a simple model represented by Equation 16. The coefficient of determination $\left(\mathrm{R}^{2}\right)$ for this model was $93.18 \%$. The response surface plots presented in Figure 7 were generated using this equation.

\section{Catalytic test: product distribution}

The evolution over time of the transesterification of TG and esterification of FFA for pomace oil catalyzed
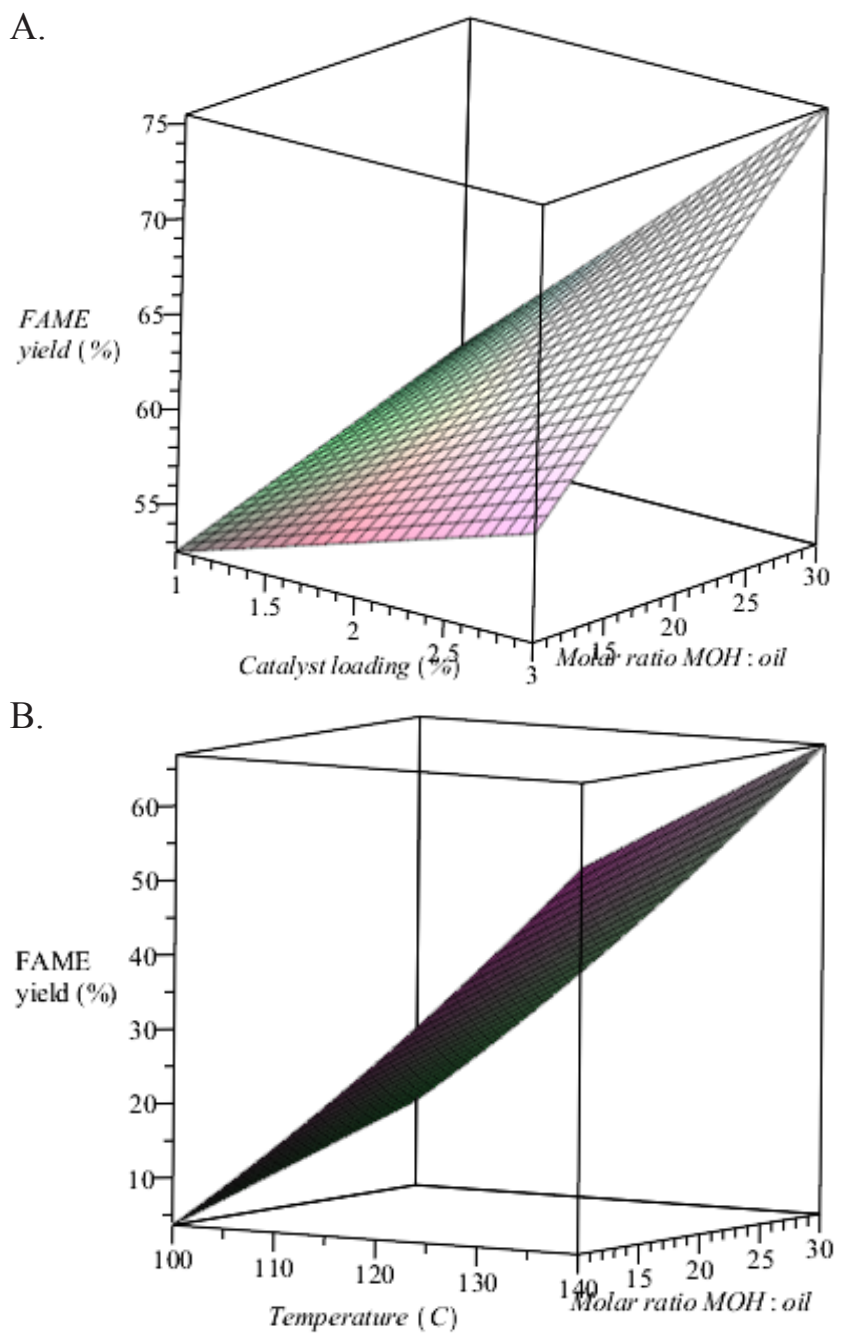

Figure 7. Fame yield in the simultaneous TG transesterification and FFA esterification of pomace oil. Variables: (a) catalyst loading and initial molar ration $\mathrm{MOH}$ :oil (at $140^{\circ} \mathrm{C}$ ), (b) temperature and initial molar ration $\mathrm{MOH}$ :oil (catalyst loading: $2 \%$ ).

by $\mathrm{Zn}$ stearate at 100 and $140{ }^{\circ} \mathrm{C}$ is shown in Figures 8 and 9 , respectively. Longer reaction time (360 $\mathrm{min}$ ) was used in order to determine equilibrium concentration.

Fig. 8 shows the evolution of the products and reactants when the reaction was performed at $100{ }^{\circ} \mathrm{C}$. The typical behavior of a reaction in series can be observed, where the concentration of TG decreases to form diglycerides (DG), which reach a maximum after $50 \mathrm{~min}$ of reaction time $(0.18 \mathrm{~mol} / \mathrm{L})$. Monoglycerides (MG) achieve their maximum concentration after $120 \mathrm{~min}(0.15 \mathrm{~mol} / \mathrm{L})$. The chemical equilibrium is achieved at $150 \mathrm{~min}$ and the final concentration of FAME is $1.18 \mathrm{~mol} / \mathrm{L}$.

When the reaction was carried out at $140{ }^{\circ} \mathrm{C}$ (Fig. 9), the product and reactant distribution followed a pattern similar to the one presented at $100{ }^{\circ} \mathrm{C}$, where the highest $\mathrm{DG}$ and $\mathrm{MG}$ concentrations were 0.18 and $0.11 \mathrm{~mol} / \mathrm{L}$ at 5 and $10 \mathrm{~min}$, respectively. It can be seen that the chemical equilibrium was achieved after 60 


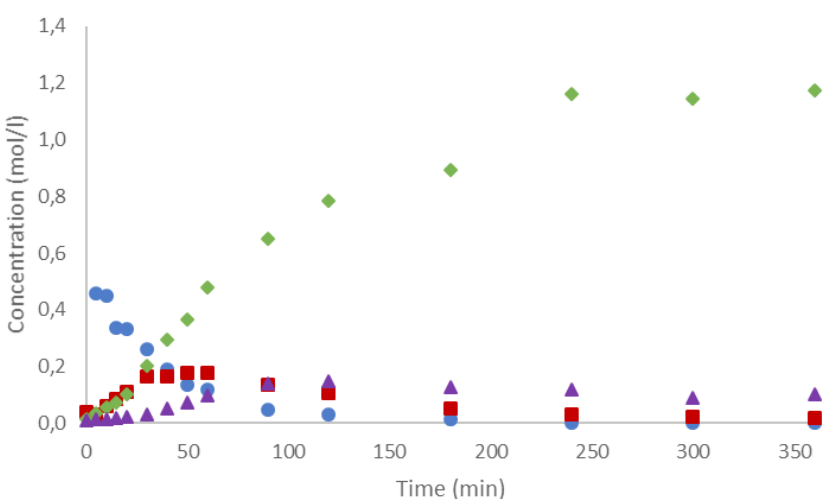

Figure 8. Transesterification of pomace oil at $100^{\circ} \mathrm{C}$ : evolution of products and reactants over time (catalyst loading: 3\%, initial $\mathrm{MOH}$ :oil molar ratio: 30). References: •triglycerides, $\square$ diglycerides, $\diamond$ FAME $\Delta$ monoglycerides.

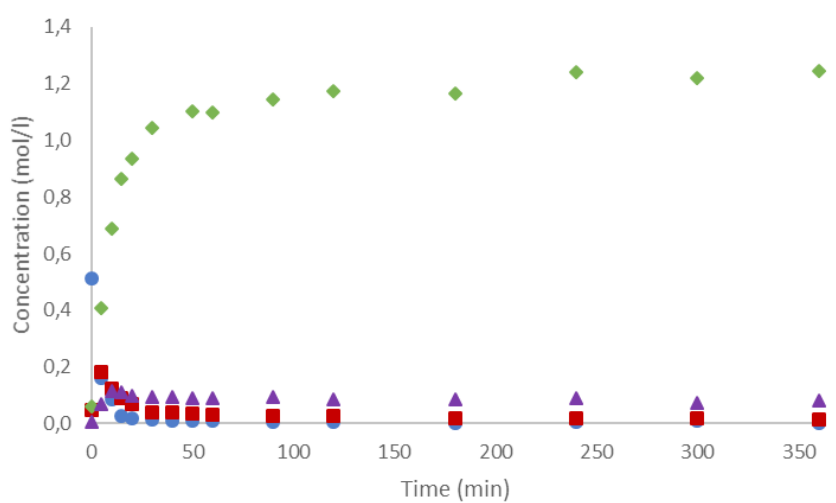

Figure 9. Transesterification of pomace oil at $140{ }^{\circ} \mathrm{C}$ : evolution of products and reactants over time (catalyst loading: 3\%, initial MOH:oil molar ratio: 30). References: •triglycerides, - diglycerides, $\diamond$ FAME $\Delta$ monoglycerides.

min. At this reaction time, the final concentration of FAME is $1.24 \mathrm{~mol} / \mathrm{L}$.

Regarding the esterification reaction, shown in Figure 10 , at $100{ }^{\circ} \mathrm{C}$ the equilibrium concentration was reached after 30 minutes and it was $\sim 0.015 \mathrm{~mol} / \mathrm{L}$ of oleic acid. On the other hand, at $140{ }^{\circ} \mathrm{C}$ the equilibrium concentration of FFA was $0.012 \mathrm{~mol} / \mathrm{L}$ at $30 \mathrm{~min}$. The corresponding fatty acid conversions are $71.2 \%$ and $81.5 \%$, also showing a higher activity for this reaction at the higher temperature.

The non-polar phase was separated from the reaction medium by decanting, and then it was water washed. When the reaction was performed at $140{ }^{\circ} \mathrm{C}$, the final concentrations were: TG: 0.3 , DG: $1.9, \mathrm{MG}$ : 7.1, FAME: 90.1, and FFA: $0.6 \mathrm{wt} \%$ (1.2 $\mathrm{mg} \mathrm{KOH} / \mathrm{g})$.

The maximum concentration admitted by international biodiesel standards (EN 14214) are: TG $<0.2, \mathrm{DG}<0.2, \mathrm{MG}<0.8$, FAME: $96.5 \mathrm{wt} \%$, and FFA: $0.5 \mathrm{mg} \mathrm{KOH} / \mathrm{g}$. Currently, work is underway to determine the kinetic parameters in order to optimize the operating conditions that maximize FAME yield

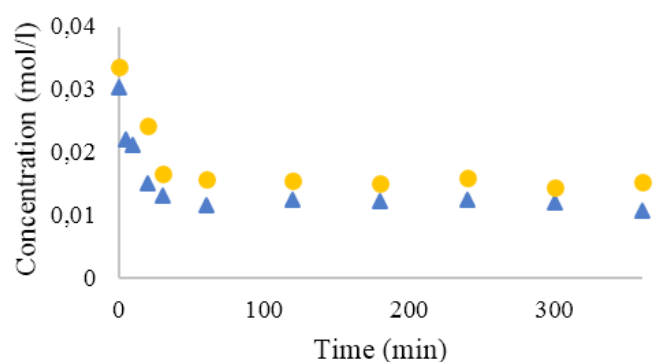

Figure 10. FFA esterification in pomace oil at $140{ }^{\circ} \mathrm{C}$ $(\boldsymbol{\Delta})$ and $100{ }^{\circ} \mathrm{C}(\bullet)$. Operating conditions: catalyst loading: 3\%, initial MOH:oil molar ratio: 30 .

and minimize concentrations of intermediate products. Since the transesterification reaction occurs in three stages that are controlled by the chemical equilibrium, the use of two reactors, with intermediate glycerol separation, is advised. Also, the esterification reaction would be positively affected because water is removed with glycerol.

\section{Kinetic model}

Figure 11 shows the dependence of $\mathrm{x}_{\mathrm{TG}} / 1-\mathrm{x}_{\mathrm{TG}}$ and $\mathrm{x}_{\mathrm{FFA}} / 1-\mathrm{x}_{\mathrm{FFA}}$ with time (Eq. 10 and 11) for the global transesterification reaction (Figure 11 a) and esterification reaction (Figure $11 \mathrm{~b}$ ) at three different temperatures $\left(140,120\right.$ and $100{ }^{\circ} \mathrm{C}$ ), with a $3 \%$ catalyst loading and an initial molar ratio of 30 (data from Table 3). The linear variation confirms that the reactions are irreversible second order in the initial period of time. The rate constants were calculated from the slopes of the linear plots of Figure 11 divided by the initial concentration. They are shown in Table 6.

Figure 12 shows the dependence of $\ln (\mathrm{k}) \mathrm{vs} 1 / \mathrm{T}$. The linear dependence shows that the Arrhenius equation
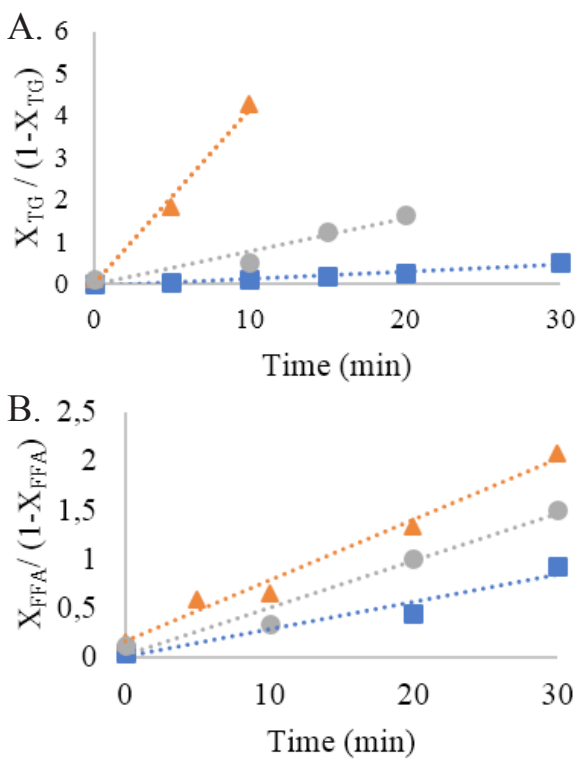

Figure 11. Irreversible second-order kinetic model for the transesterification (a) and esterification (b) reactions. References: $\Delta 140^{\circ} \mathrm{C}, \bullet 120^{\circ} \mathrm{C}, \boldsymbol{\square} 100^{\circ} \mathrm{C}$. 
Table 6. Rate constants for the irreversible secondorder kinetic model for the transesterification and esterification reactions at different temperatures.

\begin{tabular}{ccc}
\hline & $\begin{array}{c}\text { Temperature } \\
\left({ }^{\mathbf{C}} \mathbf{C}\right)\end{array}$ & $\begin{array}{c}\mathbf{k} \\
\left(\mathbf{L ~ m o l} \mathbf{~ m i n}^{-\mathbf{1}}\right)\end{array}$ \\
\hline \multirow{3}{*}{ Transesterification } & 100 & 0.0376 \\
& 120 & 0.1707 \\
& 140 & 0.9013 \\
Esterification & 100 & 0.8103 \\
& 120 & 1.3821 \\
& 140 & 1.7816 \\
\hline
\end{tabular}

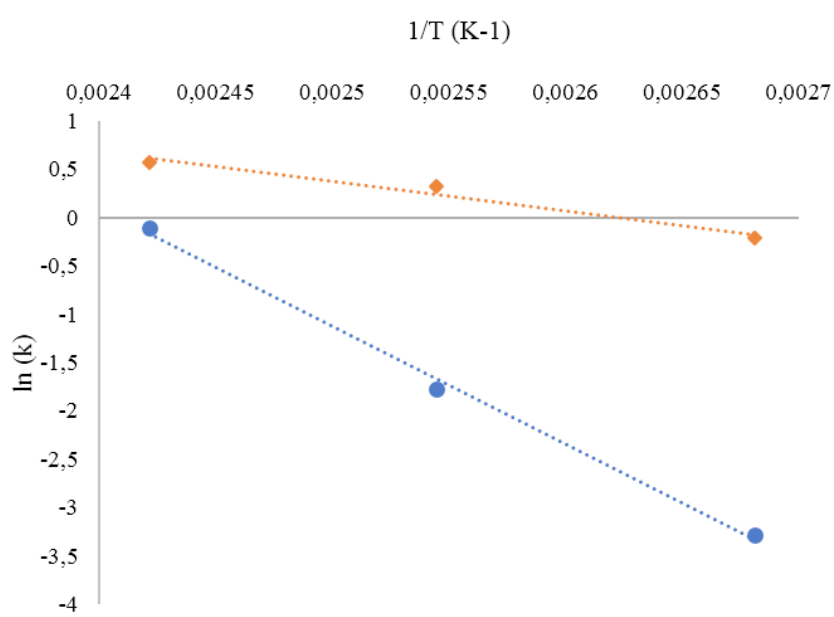

Figure 12. Arrhenius plot of the reaction rate vs. temperature for the irreversible second-order model of transesterification and esterification reactions. References: • transesterification, esterification.

(Eq. 16) can be applied to determine the activation energy of both reactions.

$\mathrm{k}=\mathrm{Ae}^{-\mathrm{E}_{\mathrm{a}} / \mathrm{RT}}$

where $\mathrm{A}$ is the pre-exponential factor, $\mathrm{E}_{\mathrm{a}}$ is the activation energy, $\mathrm{T}$ is the temperature and $\mathrm{R}$ is the gas constant. The activation energies were calculated to be 91.91 and $25.03 \mathrm{~kJ} / \mathrm{mol}$ for the irreversible second-order transesterification and esterification, respectively. A good agreement was found between experimental and theoretical results. For example, at $140{ }^{\circ} \mathrm{C}$ with $3 \%$ catalyst loading and initial molar ratio of 30 , the TG conversion obtained by Eq. 11 is $94 \%$, while in Table 3 the corresponding conversion is $98 \%$ and the calculated $\mathrm{X}_{\mathrm{FFA}}$ is $65 \%$ while the experimental one is $67 \%$.

Stamenkovic et. al (2008) found the activation energy for the methanolysis reaction of sunflower oil using $\mathrm{KOH}$ as catalyst to be $53.5 \mathrm{~kJ} / \mathrm{mol}$. Using $\mathrm{NaOH}$ as catalyst and soybean oil an activation energy was obtained between 23.7 and $83.1 \mathrm{~kJ} / \mathrm{mol}$ (Noureddini and Zhu, 1997). On the other hand, using calcium ethoxide as a heterogeneous catalyst in the soybean oil transesterification, an activation energy was found of $54.15 \mathrm{~kJ} / \mathrm{mol}$ (Liu et al., 2008).
In the esterification of waste cooking oil with ethanol, the activation energy was $36.62 \mathrm{~kJ} / \mathrm{mol}$ using sulphuric acid as catalyst (Neumann et al., 2016). The activation energy calculated for the esterification reaction is considerably lower than that found for the transesterification reaction. This agrees with the information found in the literature (Konwar et al., 2016).

\section{CONCLUSIONS}

This work showed theresults of thetransesterification of the triglycerides and the esterification of the FFA in olive pomace oil with zinc stearate as catalyst.

The used crude alperujo oil was a dark green liquid with a strong characteristic odor, being oleic acid the predominant fatty acid (55\%) followed by palmitic acid (20\%). The iodine value of the sample was 75 , the acid value was $2.3 \mathrm{mg} \mathrm{KOH} / \mathrm{g}$ oil, the calculated peroxide value was $8.7 \mathrm{meq} / \mathrm{kg}$ oil and the water content $0.07 \%$.

In the crude oil, the concentration of chlorophyll pigments was $77 \mathrm{mg}$ pheophytin/kg oil and the phosphorus content was $0.66 \mathrm{mg} / \mathrm{kg}$. After an optimized pretreatment with a modified clay (contact time 35 min, $\mathrm{T}: 70^{\circ} \mathrm{C}$, clay: $5 \%$ ) it was possible to remove the pigment to levels not detected and $\mathrm{P}$ concentration dropped to $0.11 \mathrm{mg} / \mathrm{kg}$.

From the Response Surface Methodology study, it was determined that the optimum operating conditions are $\mathrm{T}: 140{ }^{\circ} \mathrm{C}, \mathrm{C}: 3 \%$, MR:30. Under these conditions, $98 \%$ and $67 \%$ triglyceride and FFA conversions were achieved, with $84 \%$ of FAME yield at $30 \mathrm{~min}$ of reaction time.

To sum up, the biodiesel production as described in the present work can be considered a greener procedure than the conventional industrial process because crude olive pomace is a non-edible and lowcost by-product and, Zn carboxylate can be considered an environmentally friendly catalyst that can operate under mild conditions and short reaction times.

\section{ACKNOWLEDGMENTS}

The authors thank the Agencia Nacional de Promoción Científica y Tecnológica (National Agency of Scientific and Technological Promotion, Argentina) and the Consejo Nacional de Investigaciones Científicas y Técnicas (National Council for Scientific and Technological Research, CONICET) for the financial support. The authors are also grateful to Olivsan and Refil S.A. by the donation of the crude pomace oil and the Tonsil clay, respectively.

\section{REFERENCES}

Abu-Jrai, A.M., Jamil, F., Al-Muhtaseb, A.H., Baawain, M., Al-Haj, L., Al-Hinai, M., Al-Abri, M., Rafiq, S., Valorization of waste Date pits 
biomass for biodiesel production in presence of green carbon catalyst, Energ. Convers. Manage., 135, 236-243 (2017). https://doi.org/10.1016/j. enconman.2016.12.083

Alhamed Y.A.S., Al-Zahrani A.A., Techno-economical Evaluation of Oil Recovery and Regeneration of Spent Bleaching Clay, Eng. Sci., 11, 115-126 (1999). https://doi.org/10.4197/Eng.11-2.10

Apostolakou, A.A., Kookos, I.K., Marazioti, C., Angelopoulos, K.C., Techno-economic analysis of a biodiesel production process from vegetable oils, Fuel Process. Technol., 90, 1023-1031 (2009). https://doi.org/10.1016/j.fuproc.2009.04.017

Bajaj, A., Lohan, P., Jha, P.N., Mehrotra, R., Biodiesel production through lipase catalyzed transesterification: a review, J. Mol. Catal. B: Enzym., 62, 9-14 (2010). https://doi.org/10.1016/j. molcatb.2009.09.018

Barbaro, B., Toietta, G., Maggio, R., Arciello, M., Tarocchi, M., Galli, A., Balsano, C., Effects of the olive-derived polyphenol oleuropein on human health, Int. J. Mol. Sci., 15, 18508-18524 (2014). https://doi.org/10.3390/ijms151018508

Barman, S., Vasudevan, S., Contrasting melting behavior of zinc stearate and zinc oleate, J. Phys. Chem. B, 110, 651-654 (2006). https://doi. org/10.1021/jp055814m

Besset, D., Object-oriented implementation of numerical methods: an introduction with Java and Smalltalk. Morgan Kaufmann (2001).

Bonet-Ragel, K., Canet, A., Benaiges, M.D., Valero, F., Synthesis of biodiesel from high FFA alperujo oil catalyzed by immobilised lipase, Fuel, 161, 12-17 (2015). https://doi.org/10.1016/j.fuel.2015.08.032

Boukerroui,A.,Ouali,M.,Regenerationofaspentbleaching earthanditsreuse in the refining ofan edible oil, J.Chem. Technol. Biotechnol., 75, 773,776 (2000). https://doi. org/10.1002/1097-4660(200009)75:9\%3C773::AIDJCTB287\%3E3.0.CO;2-L

Che, F., Sarantopoulos, I., Tsoutsos, T., Gekas, V., Exploring a promising feedstock for biodiesel production in Mediterranean countries: A study on free fatty acid esterification of olive pomace oil, Biomass Bioenergy, 36, 427-431 (2012). https:// doi.org/10.1016/j.biombioe.2011.10.005

Chhetri, A.B., Watts, K.C., Islam, M.R., Waste Cooking Oil as an Alternate Feedstock for Biodiesel Production, Energies, 1, 3-18 (2008). https://doi. org/10.3390/en 1010003

Demirbas, A., Progress and recent trends in biofuels, Progress in Energy and Combustion Science, 33, 1-18 (2007). https://doi.org/10.1016/j. pecs.2006.06.001

Foletto, E.L., Alves, C.C.A., Sganzerla L.R., Porto, L.M., Regeneration and utilization of spent bleaching clay, Lat. Am. Appl. Res., 32, 205-208 (2002).
Haas, M.J., McAloon, A.J., Yee, W.C., Foglia, T.A., A process model to estimate biodiesel production costs, Bioresour. Technol., 97, 671-678 (2006). https://doi.org/10.1016/j.biortech.2005.03.039

Hajjari, M., Tabatabaei, M., Aghbashlo, M., Ghanavati, H., A review on the prospects of sustainable biodiesel production: A global scenario with an emphasis on waste-oil biodiesel utilization, Renew. Sust. Energ. Rev., 72, $445-464$ (2017). https://doi. org/10.1016/j.rser.2017.01.034

Hernández, D., Astudillo, L., Gutiérrez, M., Tenreiro, C., Retamal, C., Rojas, C., Biodiesel production from an industrial residue: alperujo, Ind. Crops Prod., 52, 495-498(2014). https://doi.org/10.1016/j. indcrop.2013.10.051

Hill, J., Nelson, E., Tilman, D., Polasky, S., Tiffany, D., Environmental, economic, and energetic costs and benefits of biodiesel and ethanol biofuels, PNAS, 30, 11206-11210 (2006). https://doi.org/10.1073/ pnas.0604600103

Huang, Y., Chang, J.I., Biodiesel production from residual oils recovered from spent bleaching earth, Renew. Energ., 35, 269-274 (2010). https://doi. org/10.1016/j.renene.2009.07.014

Jefferson, M., Sustainable energy development: performance and prospects, Renew. Energy, 31, 571-582 (2006).

Jurado, F., Cano, A., Carpio, J., Modelling of combined cycle power plants using biomass, Renewable Energy, 28, 743-753 (2003). https://doi. org/10.1016/j.renene.2005.09.002

Komers, K., Machek, J., Stloukal, R., Biodiesel from rapeseed oil and $\mathrm{KOH}$. 2. Composition of solution of $\mathrm{KOH}$ in methanol as reaction partner of oil, Eur. J. Lipid Sci. Technol., 103, 359-362 (2001). https://doi.org/10.1002/1438$9312(200106) 103: 6 \% 3$ C 359 : : A I D EJLT359\%3E3.0.CO;2-K

Konwar, L.J., Wärnå, J., Mäki-Arvela, P., Kumar, N., Mikkola, J.P., Reaction kinetics with catalyst deactivation in simultaneous esterification and transesterification of acid oils to biodiesel (FAME) over a mesoporous sulphonated carbon catalyst, Fuel, 166, 1-11 (2016). https://doi.org/10.1016/j. fuel.2015.10.102

Kumar, D., Singh, B., Korstad, J., Utilization of lignocellulosic biomass by oleaginous yeast and bacteria for production of biodiesel and renewable diesel, Renew. Sustainable Energy Rev., 73, 654-67 (2017). https://doi.org/10.1016/j.rser.2017.01.022

Lama-Muñoz, A., Alvarez-Mateos, P., RodríguezGutierrez, G., Montaña Durán-Barrantes, M.M., Fernandez-Bolaños, J., Biodiesel production from olive pomace oil of steam-treated alperujo, Biomass Bioenergy, 67, 443-450 (2014). https:// doi.org/10.1016/j.biombioe.2014.05.023 
Lerma-Garcia, M.J., Ramis-Ramos, G., HerreroMartinez, J.M., Simo-Alfonso, E.F., Authentication of extra virginoliveoils by Fourier transform infrared spectroscopy, Food Chem., 118, 78-83 (2010). https://doi.org/10.1016/j.foodchem.2009.04.092

Lim, B.P., Maniam, G.P., Hamid, S.A., Biodiesel from Adsorbed Waste Oil on Spent Bleaching Clay using $\mathrm{CaO}$ as a Heterogeneous Catalyst, Eur. J. Sci. Res., 33, 347-357 (2009).

Liu, X., Piao, X., Wang, Y., Zhu, S., Calcium Ethoxide as a Solid Base Catalyst for the Transesterification of Soybean Oil to Biodiesel, Energy Fuels, 22, 13131317 (2008). https://doi.org/10.1021/ef700518h

Ma, F., Clements, L.D., Hanna, M.A., The effects of catalyst, free fatty acids, and water on transesterification of beef tallow, Trans. ASAE, 41, 1261-1264 (1998). https://doi. org/10.13031/2013.17292

Marchetti, J.M., Miguel, V.U., Errazu, A.F., Technoeconomic study of different alternatives for biodiesel production, Fuel Process. Technol., 89, 740-748 (2008). https://doi.org/10.1016/j. fuproc.2008.01.007

Marjanovic, A.V., Stamenkovic, O.S., Todorovic, Z.B., Lazic, M.L., Veljkovic, V.B., Kinetics of the base-catalyzed sunflower oil ethanolysis, Fuel, 89, 665-671 (2010). https://doi.org/10.1016/j. fuel.2009.09.025

McKendry, P., Energy production from biomass (part 1): overview of biomass, Bioresour. Technol., 83, 37-46 (2002). https://doi.org/10.1016/S09608524(01)00118-3

Naik, S.N., Goud, V.V., Rout, P.K., Dalai, A.K., Production of first and second generation biofuels: A comprehensive review, Renewable and Sustainable Energy Reviews, 14, 578-597 (2010). https://doi. org/10.1016/j.rser.2009.10.003

Neumann, K., Wertha, K., Martín, A., Górak, A., Biodiesel production from waste cooking oils through esterification: Catalyst screening, chemical equilibrium and reaction kinetics, Chem. Eng. Res. Des., 107, 52-62 (2016). https://doi.org/10.1016/j. cherd.2015.11.008

Noureddini H., Zhu D., Kinetics of transesterification of soybean oil, J. Am. Oil Chem. Soc., 74, 14571463 (1997). https://doi.org/10.1007/s11746-9970254-2

Nunes, A.A., Franca, A.S., Oliveira, L.S., Activated carbons from waste biomass: An alternative use for biodiesel production solid residues, Bioresource Technology, 100, 1786-1792 (2009). https://doi. org/10.1016/j.biortech.2008.09.032

Ouachab N., Tsoutsos, T., Study of the acid pretreatment and biodiesel production from olive pomace oil, J. Chem. Technol. Biotechnol., 88, 1175-1181 (2013). https://doi.org/10.1002/jctb.3940
Rajaeifar, M.A., Akram, A., Ghobadian, B., Rafiee, S., Heijungs, R., Tabatabaei, M., Environmental impact assessment of olive pomace oil biodiesel production and consumption: A comparative lifecycle assessment, Energy, 106, 87-102 (2016). https://doi.org/10.1016/j.energy.2016.03.010

Reinoso, D.M., Damiani, D.E., Tonetto, G.M., Efficient production of biodiesel from low-cost feedstock using zinc oleate as catalyst, Fuel Process. Technol., 134, . 26-31 (2015). https://doi. org/10.1016/j.fuproc.2015.03.003

Reinoso, D.M., Damiani, D.E., Tonetto, G.M., Zinc carboxylic salts used as catalyst in the biodiesel synthesis by esterification and transesterification: Study of the stability in the reaction medium, Appl. Catal. A Gen., 449, 88-95 (2012). https://doi. org/10.1016/j.apcata.2012.09.014

Reinoso, D.M., Damiani, D.E., Tonetto, G.M., Zinc glycerolate as a novel heterogeneous catalyst for the synthesis of fatty acid methyl esters, Appl. Catal. B, 144, 308-316 (2014). https://doi. org/10.1016/j.apcatb.2013.07.026

Reinoso, D.M., Ferreira, M.J., Tonetto, G.M., Study of the reaction mechanism of the transesterification of triglycerides catalyzed by zinc carboxylates, J. Mol. Catal. A: Chem., 377, 29-41 (2013). https:// doi.org/10.1016/j.molcata.2013.04.024

Roig, A., Cayuela, M.L., Sánchez-Monedero, M.A., An overview on olive mill wastes and their valorisation methods, Waste Management, 26, 960-969 (2006). https://doi.org/10.1016/j. wasman.2005.07.024

Roman, A., Che Man, Y.B., Fourier transform infrared (FTIR) spectroscopy for analysis of extra virgin olive oil adulterated with palm oil, Food Res. Int., 43, 886-892 (2010). https://doi.org/10.1016/j. foodres.2009.12.006

Rousseaux, M.C., Benedetti, J.P., Searles, P., Leaflevel responses of olive trees (Olea europaea) to the suspension of irrigation during the winter in an arid region of Argentina, S. Sci. Hort., 115, 135-141 (2008). https://doi.org/10.1016/j. scienta.2007.08.005

Sánchez Moral, P., Ruiz Méndez, M., Production of pomace olive oil, Grasas Aceites, 57, 47-55 (2006). https://doi.org/10.3989/gya.2006.v57.i1.21

Stamenkovic, O.S., Todorovic, Z.B., Lazic, M.L., Veljkovic, V.B., Skala, D.U., Kinetics of sunflower oil methanolysis at low temperatures, Bioresour. Technol., 99, 1131-1140 (2008). https://doi. org/10.1016/j.biortech.2007.02.028

Tomei, J., Uphamb, P., Argentinean soy-based biodiesel: an introduction to production and impacts, Energy Policy, 37, 3890-3898 (2009). https://doi.org/10.1016/j.enpol.2009.05.031 
Vicente, G., Bautista, L.F., Rodríguez, R., Gutiérrez, F.J., Sádaba, I., Ruiz-Vázquez, R.M., TorresMartínez, S., Garre, V., Biodiesel production from biomass of an oleaginous fungus, Biochem. Eng. J., 48, 22-27 (2009). https://doi.org/10.1016/j. bej.2009.07.014

Vicente, G., Martínez, M., Aracil, J., Integrated biodiesel production: a comparison of different homogeneous catalysts systems, Bioresour. Technol., 92, 297-305 (2004). https://doi. org/10.1016/j.biortech.2003.08.014

West, A.H., Posarac, D., Ellis, N., Assessment of four biodiesel production processes using HYSYS Plant, Bioresour. Technol., 99, 6587-6601, (2008). https://doi.org/10.1016/j.biortech.2007.11.046

Yüsel, Y., Biodiesel production from pomace oil by using lipase immobilized onto olive pomace,
Bioresour. Technol., 102, 3977-3980 (2011). https://doi.org/10.1016/j.biortech.2010.12.001

Zhang, Y., Dubé, M.A., McLean, D.D., Kates, M., Biodiesel production from waste cooking oil: 1 process design and technological assessment, Bioresour. Technol., 89, 1-16 (2003). https://doi. org/10.1016/S0960-8524(03)00040-3

Zhang, Y., Dubé, M.A., McLean, D.D., Kates, M., Biodiesel production from waste cooking oil: 2 economic assessment and sensitivity analysis, Bioresour. Technol., 90, 229-240 (2003). https:// doi.org/10.1016/S0960-8524(03)00150-0

Zubir, M.I., Chin, Z.Y., Kinetics of Modified Zirconiacatalyzed Heterogeneous Esterification Reaction for Biodiesel Production, J. Applied Sci., 10, 2584-2589 (2010). https://doi.org/10.3923/ jas.2010.2584.2589 
